\title{
Study on Interior Space Optimization of Green Affordable Housing in Cold Region
}

\author{
Junyan Dong ${ }^{1,2}$, Bomin Zheng ${ }^{1 *}$, Yupi Fu ${ }^{1}$, and Kechao $\mathrm{Li}^{1}$ \\ ${ }^{1}$ School of Architecture and Design, Changchun Institute of Technology, Changchun, Jilin Province, 130000, China \\ ${ }^{2}$ School of Institute, The Tourism College of Changchun University, Changchun, Jilin Province, 130000, China
}

\begin{abstract}
With the construction of a large number of affordable housing and the development of green buildings, the design of green affordable housing has become a new concern and research topic in China's residential architectural design, and the interior design of affordable housing has become a top priority. This article takes Changchun city as an example, through the research of affordable housing in Changchun, visit, found the main problems existing in the status quo, in view of the problems put forward housing interior space design optimization principle, and according to the design principles of indoor space scale, provides a good green indoor living environment for green residential tenants in cold areas.
\end{abstract}

\section{Introduction}

Indemnificatory housing is a special type of housing provided by the Chinese government for low-income families with housing difficulties. It has the nature of social security to improve people's livelihood and promote social stability. China's indemnificatory housing is still in the early stage of development. With the development of society and the increasing demand of residents for improving the quality of life, the integration of the concept of indemnificatory housing and green building has become the focus of the residential architectural design. Since the "green building evaluation standard" was issued in 2006, with the introduction of relevant rules and supporting policies, and the establishment of local green building logo management institutions, the concept of green building has gradually been recognized by all sectors of society.

The construction of indemnificatory housing has become a development trend of green building. It is expected that indemnificatory housing will become a green building project in the future, as shown in Figure 1.

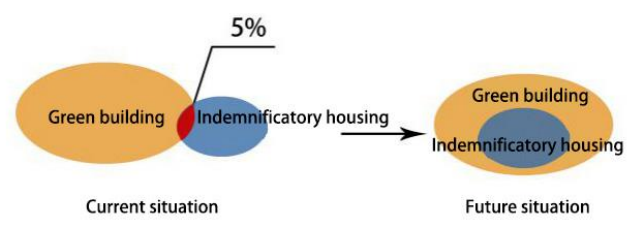

Fig. 1. Relationship between indemnificatory housing and green building
Green indemnificatory housing refers to creating the most comfortable housing space in the most economical and safe way in the whole life cycle of the house, from site selection, planning, scheme, construction, putting into use to the final demolition. Truly realize the harmonious coexistence of human, architecture, and environment. China's climate zone spans a large area, and the climate difference between the north and the south is obvious. The building design in the severe cold area has a strong regional character. The basic requirement of the building in this area is cold insulation and antifreeze, so the indoor insulation design of indemnificatory housing is particularly important in the severe cold area. [1,2]

\section{The main problems existing in the interior space environment of current indemnificatory housing -- Taking Changchun as an example}

\subsection{Requirements of regional characteristics for green affordable housing}

Changchun City is located in the cold area of China, in the hinterland of the Northeast China Plain. It belongs to the continental monsoon climate area of the north temperate zone. It is dry and windy in spring; warm and rainy in summer; large temperature difference between day and night in autumn; cold and long in winter. The impacts of Changchun's climate characteristics on housing are as follows:

(1) Changchun has a obvious climate characteristics in four seasons, with large temperature difference between day and night. The drying of clothes and bedding at home has a great demand for balcony

\footnotetext{
"Corresponding author: 453846534@163.com
} 
space. However, the South and North balconies in severe cold area absorb heat in summer. They dissipate heat in winter, which is not energy-saving and does not meet the design requirements of indoor heat preservation and insulation.

(2) Most of the families living in the northern cold area have the habit of pickle curing in winter. The pickle making process has higher requirements for time and temperature, and also has taste. Due to the limitation of the indemnificatory housing area, the lack of such space leads to the confusion of the cleaning area and the deterioration of the indoor environment.

(3) Due to the long winter time in severe cold area, the heating period of Changchun City is from midOctober to mid-April of the next year. At present, there are two heating modes: heating by radiator and heating by floor heating. Because of the high cost of floor heating, the thickness of heating equipment and cooling space should be fully considered in the design of bay depth of most indemnificatory houses in Changchun.

\subsection{The main problems existing in the residence of protected users}

According to the data statistics released by Changchun housing security network, the minimum security standard for Changchun residents can reach 620 yuan per month from 130 yuan per capita in 1997 to 305 yuan per capita in 2009 to now in 2018, as shown in Table 1:

Table 1. The minimum living standard of Changchun in 2018.

\begin{tabular}{|c|c|c|c|}
\hline \multicolumn{2}{|c|}{$\begin{array}{c}\text { Urban minimum living } \\
\text { standard (monthly per capita) }\end{array}$} & $\begin{array}{c}\text { Rural minimum living standard } \\
\text { (annual per capita) }\end{array}$ \\
\hline Changchun & 620 & Changchun & 4920 \\
\hline Shuangyang & 430 & Shuangyang & 3804 \\
\hline Jiutai & 430 & Jiutai & 3804 \\
\hline Yushu & 390 & Yushu & 3650 \\
\hline Nongan & 430 & Nongan & 3650 \\
\hline Huide & 415 & Huide & 3710 \\
\hline
\end{tabular}

The number of guaranteed population is decreasing and the amount of guarantee is increasing. With the construction of national indemnificatory housing, the living environment of the guaranteed population has improved. However, due to the initial exploration of indemnificatory housing, there are still the following problems:

(1) Many multi-storey houses have been added without permission, resulting in insufficient building spacing, insufficient sunshine, insufficient indoor sunshine in the long winter, indoor temperature not up to the standard requirements, not heat preservation and energy saving.

(2) Because of the restriction of economic conditions, many families choose not to pay the heating fee. In winter, there is almost no temperature difference between inside and outside of the room. Using the stove to heat, there is a great potential risk of environmental pollution. Every year, carbon monoxide poisoning occurs.
(3) The wall thickness of the houses is not up to the standard. Many indemnificatory houses in Changchun have a wall thickness of only $120 \mathrm{~mm}$, which can't resist the winter in the severe cold area. Moreover, many indemnificatory houses don't have a thermal insulation layer, which leads to the excessive loss of building energy consumption and can't meet the basic requirements of thermal insulation and antifreeze. Moreover, many households in a corridor have opposite doors, so the sound insulation effect is very poor.

\section{Optimization principle of interior space design of green indemnificatory housing}

The optimization design of green indemnificatory housing interior space should fully consider the regional characteristics, and consider the applicable population so that the indemnificatory housing can meet the living requirements of the minimum security population, and at the same time, truly realize green energy saving.

\subsection{Passive technology priority principle}

Green building technology is divided into two types: active and passive. The principle of passive technology priority should be considered at the beginning of design for indemnificatory housing. Passive housing mainly achieves the performance of heat preservation, heat insulation and energy saving through the construction of the building itself, and uses other natural energy such as solar energy to provide heat for the interior of the housing, as well as clean and renewable energy. Combined with the climate characteristics of the cold area, the orientation of the building and the size of the window opening are very important for collecting solar energy.[3]

\subsection{Principle of practical technology priority}

When adopting the green affordable housing technology, we should pay attention to the principle of practical, mature technology priority, reasonable house type design, maintenance structure optimization, use of energy-saving furniture, matching of water-saving appliances, etc., and also consider the design of indoor three-dimensional space, the use of vertical space mezzanine and composite furniture comprehensive design. In order to save land resources, an efficient space system must be adopted to make use of the surrounding resources according to local conditions. The energy-saving design of indemnificatory housing in China's severe cold area must ensure the thermal insulation performance and ventilation and lighting conditions of the residential room, ensure the length of sunshine in winter, and improve the building's ability to adapt to the climate and the efficiency of using natural resources. 


\subsection{Pay attention to the intensive development of the economy}

In the construction cost of indemnificatory housing, the cost of land acquisition accounts for a large proportion. Because the payment ability of the service object of indemnificatory housing is limited, it is necessary to explore a set of experience of economic priority and land-intensive use.[4] Under the premise of ensuring the smooth indoor lighting and ventilation, the green indemnificatory housing in the cold area can adopt the plane form of considerable depth and narrow width to improve the plane coefficient of the housing.[5]

\subsection{Comfort design principles}

At the beginning of the design of indemnificatory housing, the user's space and comfort should be considered. The length and thickness of the outer wall and the size of the opening should also be considered under the premise of ensuring the basic performance of the interior. The privacy and continuity of the space should be paid attention to. The living area of indemnificatory housing is limited. The reasonable compression, utilization, and distribution of space should be considered in the design. In addition, considering the climate characteristics and living habits of the cold area, the storage space for the pickle jar should be set, and the storage space for the bedroom should be increased.

\section{The design of main space scale of green indemnificatory housing}

\subsection{Bedroom}

The primary function of the bedroom is rest, which should meet the needs of rest, storage, and learning. It is a private space. In addition to the size of the furniture, the design of the bedroom should also consider the behavior space of people. According to the relevant size of the data set and furniture, the plan of double bedroom and single bedroom of Changchun indemnificatory housing is drawn, as shown in Figure 2, to meet the basic functions and Under the condition of heat preservation and insulation, the land resources can be used economically and efficiently with the smallest area.
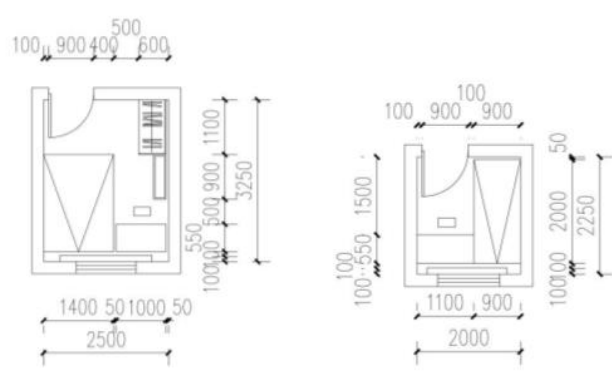

Fig. 2. Double bedroom single bedroom layout

\subsection{Kitchen}

The design of the kitchen should first consider the users, and consider the size of various kitchenware, on the premise of meeting the function, improve the user's comfort, according to the relevant data, respectively draw the "L" shape and "I" shape kitchen small use area map, as shown in Figure 3.

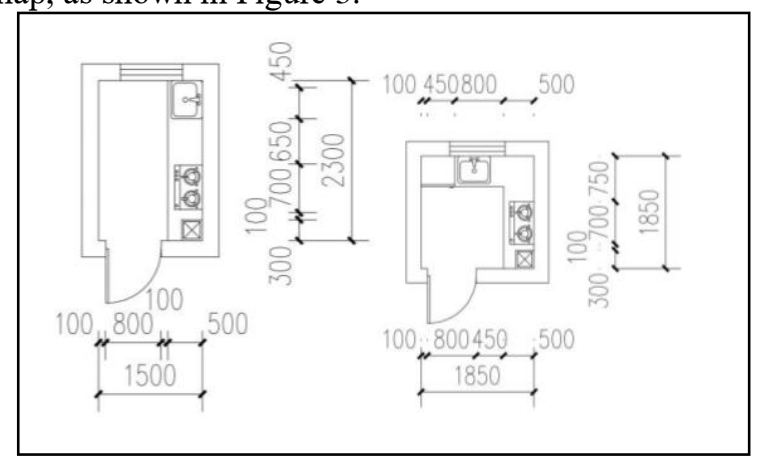

Fig. 3. "L" shape and "I" shape kitchen layout

\subsection{Bathroom}

Generally, the indemnificatory housing is limited by the area, and only one toilet is set. The toilet should meet the requirements of daily washing and washing machine space. On the premise of meeting the basic functions of the toilet, it should be drawn according to the minimum size and minimum behavior scale of the sanitary ware, as shown in figure 4.

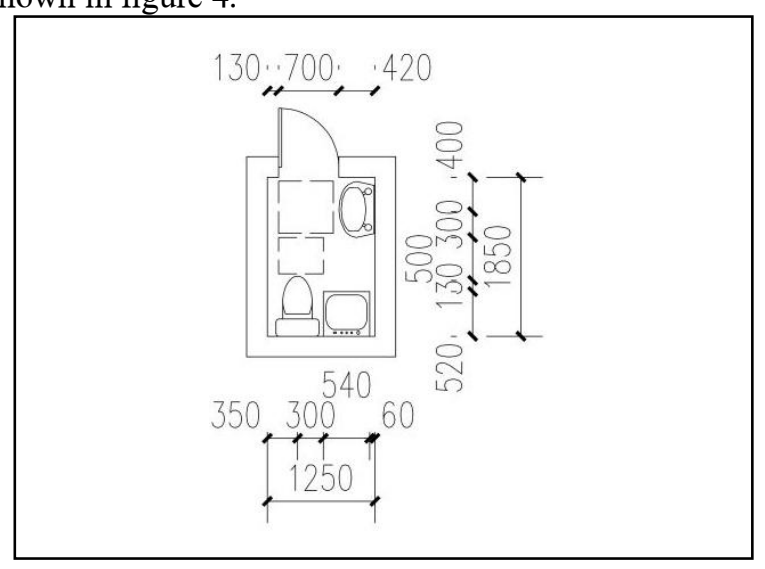

Fig. 4. Bathroom layout

\subsection{Living room}

The living room is a public area of the interior space, which can be used as a composite space, a living room and a dining room, and a tea table as a dining table. The living room can also be used as a guest bedroom. According to the research, when there are guests staying in the living room of some indemnificatory houses, the sofa can be used as a guest bedroom. According to the research, the use of the living room and the study is very popular in the market. The combination furniture of multi TV cabinet and bookshelf, as well as many folding desks, can be placed in the living room to achieve efficient use of space.[6] 


\section{Conclusions}

With the acceleration of urbanization, the ratio of the selling price of commercial housing to the annual income of the family is increasing year by year. More and more families need indemnificatory housing. The government has increased efforts to construct indemnificatory housing. However, green indemnificatory housing in China is still in the early stage of construction. There are still many problems in the optimization of internal space design. The indemnificatory housing in severe cold areas is obviously affected by regional characteristics. In this paper, based on the existing main problems of the residents, starting from the demand, combined with green building, taking Changchun City as an example, the interior space of indemnificatory housing in cold area is optimized.

All aspects of green building technology should be considered in affordable housing. From the construction of the building itself to the use of energy-saving furniture, the indoor space environment of the residents can be improved. According to the actual situation of the residents, the optimization principle of the indoor space and the design of the main indoor space scale can be obtained, so as to provide a design method for the optimization design of the internal space of green affordable housing in severe cold area And scale reference.

\section{Acknowledgment}

This work was financially supported by Science and Technology Project Foundation of Jilin Provincial Development and Reform Commission (No. 2019C0594), Science and Technology Project Foundation of Jilin Provincial Department of Education (No. JJKH20191242KJ) and Jilin Provincial Social Science Foundation.

\section{References}

1. S.Qingsong, Discussion on green building design method of indemnificatory housing, China Housing Facilities,31(2019).

2. D. Junyan, F.Yupi, Application of green building technology in cold region cities, E3S Web of Conferences 136,03013(2019).

3. T.Huifeng, R.Jianqing, Discussion and practice of green building design method for indemnificatory housing, Housing Science, 4(2013).

4. P.Yi, Z.Li ,The practice and Enlightenment of green public housing construction in Denmark, New Architecture 4(2019).

5. Y. Zhenyang, W.Xian, Depth, bay, width and floor area ratio of commercial residence, Archicreation, 8(2003).

6. W.Qiao, Research on the optimization design of inner space of indemnificatory housing in Changchun. Jilin Jianzhu university, 6,53-58(2014). 